\title{
Stakeholder and Value Orientation in Digital Social Innovation: Designing a Digital Donation Concept to Support Homeless Neighbors
}

\author{
Larissa Gebken \\ University of Hamburg \\ gebken@informatik. \\ uni-hamburg.de
}

\author{
Paul Drews \\ Leuphana University of \\ Lüneburg \\ paul.drews@leuphana.de
}

\author{
Ingrid Schirmer \\ University of Hamburg \\ schirmer@informatik. \\ uni-hamburg.de
}

\begin{abstract}
During the first wave of COVID-19 lockdowns, the infrastructure for supporting homeless neighbors disintegrated in many countries. As one important area of support, it became difficult to provide small donations to homeless neighbors. In an action design researchbased project, as part of a national hackathon initiative and accelerator program, we contributed to the development of a digital donation concept. We frame this process as a digital social innovation for vulnerable people and highlight the need to consider stakeholder and value orientation during the design, implementation, and evaluation stages. Our findings include a reflection of the project course, a description of the developed concept, an analysis of how values shaped the design, and a formalization of learnings.
\end{abstract}

\section{Introduction}

In times of COVID-19, it has become visible again that the poorest in a society are the worst affected by crises [20]. Many organizations for homeless neighbors had to close because they could not meet the healthrelated safety standards, and many of their volunteers belong to the high-risk group. In Germany, organizations expressed two major needs during the lockdown: First, they claimed to offer immediate decentralized accommodation for homeless neighbors ${ }^{1}$, since many of these people also belong to the high-risk group and are not able to protect themselves [20]. Second, digital and contactless help is needed to enable self-protection while maintaining care. Homeless aid organizations had to reorganize their work to quickly inform and help homeless neighbors without endangering their health, but they lacked the appropriate concepts and tools.
During Germany's national COVID-19 hackathon \#WirVsVirus, various teams worked on generating ideas to support homeless neighbors during the pandemic in the problem area of care provision for vulnerable groups [1]. In this paper, we focus on the initiative OpenStreetPay, which started during the hackathon. One of the authors actively participates in this (still ongoing) project. This allowed us to access the data and people of this initiative. The goal of OpenStreetPay is to enable digital donations and contactless payments for homeless neighbors while taking into account their limited resources and living conditions (e.g., no permanent residence, no permanent access to electricity, the Internet, or mobile devices). OpenStreetPay is a concept that includes a digital donation and payment system to enable contactless donations to homeless neighbors. The donation can be made via the donor app or a webpage. The donation receipt and the store payment are processed via a card (SmallChangeCard) and the merchant app. In addition, the concept includes collaboration aspects between homeless neighbors and aid organizations. We frame the initiative as the development of a digital social innovation (DSI) according to the UN Sustainable Development Goals, as it aims at taking care of the needs of vulnerable people [19]. To realize the DSI, we draw on approaches from the field of value sensitive design (VSD). Hence, our paper addresses two research questions:

RQ1: How can we design a concept that allows digital donations for homeless neighbors?

RQ2: What can be learned from the process of developing value-based and stakeholder-oriented digital social innovations for vulnerable people?

We contribute to information systems (IS) research by presenting a digital donation concept and a formalization of learnings related to this concept (RQ1). We also provide in-depth descriptions of how values influenced the design, with a reflection of the learnings

\footnotetext{
${ }^{1}$ Homeless neighbor is the short form of "neighbors who experience homelessness." It is used to emphasize the perspective on people not homelessness [I5].
} 
related to using VSD to structure the process of developing a DSI for vulnerable people that follows stakeholder and value orientation (RQ2).

\section{Related research}

The related literature for our study stems from three streams: First, related to our first research question, we investigated recent studies about digital innovations in the field of support for homeless neighbors. Second, we position our study in the field of DSI and the area of DSI for vulnerable groups. Third, we consider existing research on VSD, as DSI studies and our action design research (ADR) project guided us toward the strong relevance of considering values in the design process.

The reasons for becoming homeless are multilayered, and it can cause issues such as "reduced life expectation, health problems, discrimination, isolation and barriers to access to basic public services and benefits" [8]. To support people living in homelessness, Sowa et al. [18] highlight the important considerations for digital transformation in the field of homeless aid support (e.g., the risk of further stigmatization of needy people or the disclosure of highly sensitive information). One existing prejudice is that homeless neighbors do not have a telephone or access to the Internet. Two studies from Australia and the USA have addressed this issue. The study from Australia (with $n=95$ in 2014) showed that 68 of the participants owned a smartphone, but only $49 \%$ had a paid Internet service on their phone [12]. In the other study from the USA (with $n=461$ in 2017), the authors found that there is no digital divide between homeless and non-homeless neighbor in the same age group and that approximately $58 \%$ own a smartphone [15]. Even if there is no large divide within the age group, $42 \%$ still do not own a smartphone [15]. Nevertheless, the first apps for homeless neighbors exist to provide them with digital support. Especially in the field of CSCW and HCI, this topic has been addressed. Burrows et al. (2019) evaluated the design of the mobile web app Ask Lizzy regarding emotional concerns and thereby considering psychological aspects. The app supports homeless neighbors in Australia with information about where to find help [6]. To date, to the best of our knowledge, no study deals with analyzing or developing a digital donation concept for homeless neighbors in detail.

Therefore, we considered literature about DSI, as it serves as the broader field of research we seek to contribute to with our study. DSI is an upcoming topic in the IS field [4] and has the aim of challenging societal problems [7]. The subject areas of DSI are diverse and include (among others) education, poverty reduction, and sustainable development. Our study is related to the area of DSI for vulnerable groups. Related studies in this area employed similar methods or were even tackling the challenges of homeless neighbors. An ADR-based study by Keijzer-Broers and de Reuver [13] discusses the dimensions of developing a DSI (a service platform for health and wellbeing) for vulnerable groups (elderly people). We adapted the learnings from this study for our research: We broke down the societal problem into stakeholder problems, and we continuously reshaped digital innovation, and social practice, we involved citizens as early as possible, and we integrated a discussion of values. One project that specifically aimed at developing a DSI for the vulnerable group of homeless neighbors is called \#patchwork. This project is a field research study in which a diverse research group tried to develop a disruptive digital innovation to support homeless neighbors together with homeless aid organizations. The project ended because the homeless aid organization feared that the security of homeless neighbors might be threatened. Whittle et al. [22] identified missing shared values as one reason for members to disengage or to leave the project.

Whittle et al.'s study and the experiences in the project of our study guided us toward considering literature from the area of VSD. VSD allows us to link DSI with specific contextual factors that are relevant for consideration in the design process. Therefore, we include the field of VSD as the third research stream [17]. In the sense of VSD, innovations are always morally linked, as they support or inhibit certain values. The influence or impact is different for each technology [3]. Thus, it is necessary to critically analyze the DSI concerning its effects on society and the environment [11, 21]. Friedman [10] commenced the discussion about VSD by answering questions regarding unintentional and intentional inscription of values in IT artifacts. She hypothesizes that it is essential to include values in the development process. If there is no conscious consideration of values, the values still exist, but the discussion and reflection of them do not occur $[10,17]$. The discourse about the concept of value still exists, and the term is interpreted very differently in different disciplines [17]. In our study, we refer to Friedman's perspective, according to which "a value refers to what a person or group of people consider important in life" [11].

Through the early involvement of stakeholders and the focus on values, technical design and development should lead to a DSI that meets societal needs and lives up to its responsibility [17]. Therefore, it is essential to 
investigate different perspectives and different kinds of values [9, 11]. Friedman et al. (2008) [11] differentiate the different kinds of (human) values and describe a method to define the values of one's project.

By analyzing the existing literature, we found that research has not yet developed a well-founded understanding of which guidelines can support the development of a digital donation concept for homeless neighbors (RQ1). Furthermore, we aim at learning from studies like Whittle et al. [22] by incorporating values into the development to sustain the commitment of different stakeholder groups. Furthermore, we draw on Friedman et al. [11] to realize VSD in the DSI development process. By reflecting this approach, we seek to contribute to the realization of DSI for vulnerable groups, such as homeless neighbors, based on VSD (RQ2).

\section{Research design}

The aim of our study is to develop a concept (framed as a DSI) for digital donations for homeless neighbors (RQ1) and to reflect on the use of stakeholder orientation and values during the design process for a DSI (RQ2). We structured our study based on the ADR approach by Sein et al. [16] to enable an embedded and reflected development in the context. Our research process was structured into four stages (cf. Figure 1). In stage 1 , we formulated the problem. In stage 2 , we described the iteratively built and evaluated digital donation concept and values. In stage 3 , we reflected on our learnings, and in stage 4 , we formalized our learnings.

In stage 1, three streams of activities led to an initial understanding of the problem area. In 2019, we started to analyze the use of DSI by homeless neighbors by conducting three interviews and an analysis of existing apps. We also commenced a literature research. At the beginning of the COVID-19 crisis, one of the authors participated in the national hackathon and became a member of the OpenStreetPay project. During the initial collaboration in this project, the idea emerged that we could accompany the project from a research perspective and start an ADR-based study. The OpenStreetPay team, which consisted of 15 people at that time, started working on a concept for helping homeless neighbors with digital donations. The team had already integrated some partners within the first 48 hours of the development process to obtain feedback about the idea. For the first stage of ADR, it is necessary to formulate the problems encountered. In our project, we are working in the field of societal issues and trying to solve them with a DSI. For that, we analyzed the problem area as understanding the current situation of homeless neighbors during the hackathon and the first lockdown. Afterwards, we integrated the theoretical background based on the literature research.

In stage 2, we identified key stakeholders (groups) for OpenStreetPay. We conducted an online-based acceptance test and 11 unstructured expert interviews (nine with volunteers and employees of homeless aid organizations, a group interview with four lawyers, an interview with a money transferring company) to get initial feedback for the OpenStreetPay prototype. The questionnaire for the acceptance test was developed iteratively, and the understanding was tested with the OpenStreetPay team in each iteration. The role-specific questionnaire was structured by different stages of usage and included open and closed questions. Only fully completed questionnaires were considered. Our online survey had 98 participants $(1.02 \%$ homeless neighbors, $88.78 \%$ donors, $9.18 \%$ employees of homeless aid organizations, and $4.18 \%$ others). For the quantitative analysis, we used standard descriptive statistical methods and Python. For the qualitative analysis, we paraphrased and coded the open questions. The purpose of the 11 expert interviews was to gain a deeper understanding of participants' assessment of the concept and especially to identify potential obstacles for its realization. Two members of the OpenStreetPay team conducted the interviews. We refrained from recording these interviews, since it was often the first contact with the organization, and the team intended to establish sustainable cooperation with them. The team considered the results of the acceptance test and expert interviews in developing the values for OpenStreetPay as well as reshaping the digital donation concept. In stage 2 , the project group started a discussion about the values that should guide the process. The discussions were guided by the work on VSD by Friedman et al. [11] and KeijzerBroers and Reuver [13]. Friedman et al. approach highlight that values cannot be gathered empirically, but they are based on the interests and wishes of humans. To identify relevant values, Friedman et al. suggest conducting conceptual, empirical, and technical investigations. In the beginning, four members of the OpenStreetPay team thought individually about their five main values and what kind of impact they would have for each key stakeholder group, the team, the communication, and the technical development. These four people met online, discussed the values of each person, and searched for common ground among the different opinions. After the group found common ground, one member asked a professional to formulate these common values into simple language, ensuring 


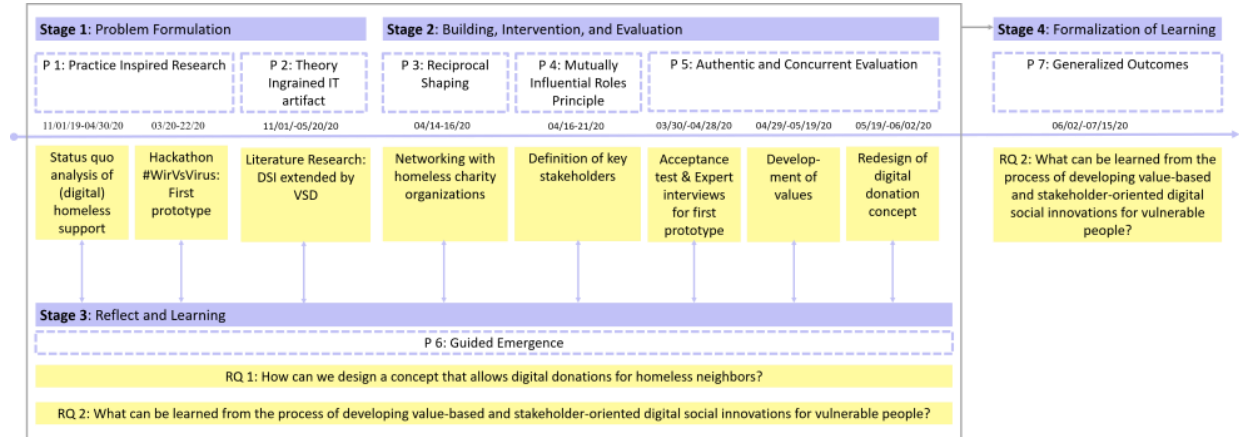

Figure 1. Overview of the four stages of ADR by Sein et al. (2011) [16] related to our activity

that everyone could understand them. The group then presented and discussed the values in the weekly team call. The team deliberately decided to follow this procedure to avoid repeated discussion of basic issues. The values were then used to reshape and reflect our digital donation concept.

In stage 3, we reflected and discussed the development so far multiple times among the authors. We first analyzed the findings iteratively to identify the key learnings by paraphrasing the main messages and the learnings from the development process.

In stage 4, we developed design principles that summarized what we had learned from our process so far and how this could help to guide other DSI developments for vulnerable groups.

For the next design loop, the first artifacts will be tested in a pilot test. This will require proceeding with care since we work in a highly sensitive environment with people who often live in difficult circumstances. We plan to involve homeless neighbors when they agree to participate and when the circumstances permit.

\section{Results \\ 4.1. Initial understanding of the situation and the focal problem}

Worldwide, more than 1.8 billion people experience homelessness [20]. Therefore, they do not have the possibility of practicing physical distancing or washing their hands regularly due to a lack of adequate access to water [20]. The living circumstances during the first COVID-19 lockdown became even worse for homeless neighbors [20]. During the lockdown, cash donations by individuals were dramatically reduced, as people stayed at home and did not meet their homeless neighbors. In the long run, COVID-19 can be seen as an additional driver for cashless payment [2]. Hence, the motivation for this project was twofold: In the short run, the idea was to establish infrastructure to maintain the possibility of donating during a lockdown. In the long run, the team expects a reduced use of cash, which renders a digital donation concept also a relevant topic for the future. With this initial understanding of the situation, we started to look for existing solutions by analyzing existing apps. Our analysis revealed that there are many different digital solutions available worldwide for supporting homeless neighbors. These solutions pursue different goals. We examined digital solutions in German and English-speaking countries and clustered them by purpose (cf. Table 1). The results of our analysis provided us with an overview of existing types of digital support. So far, most apps and websites focus on providing information or enabling digital donation support. The money is/was directly provided to the homeless neighbors in only two apps (Samaritan and $\mathrm{N}=5$ _Helping Heart). Also, while screening the apps, we found design decisions that can be discussed critically when considering the value-based perspective of a solution. For example, the app Samaritan uses the stories and pictures of homeless neighbors in combination with their local position to generate higher amounts of donations. The positive aspect of this kind of marketing is that people can tell their stories on their own. The negative aspect is that stereotypes can be stabilized, donation recipients are dependent on the donor's arbitrariness, and sensitive data (position, name, etc.) of the donation recipient can be used against them $[18,22]$. The $\mathrm{N}=5$ _Helping Heart app has been discontinued.

As an additional source for framing our initial understanding of the situation, we used data gathered in the interviews we led prior to the COVID-19 crisis. In an interview, a homeless neighbor argued that apps that do not fulfill his needs would be uninstalled quickly. Especially if the information was not up-to-date, it could have many negative implications for him and lead to mistrust [I0]. Further, the interviewee stressed the importance of good usability for people with disabilities [I0]. We also considered the perspective of a director of a large homeless aid organization app. He stated that many homeless neighbors do not have time to 


\begin{tabular}{|l|l|}
\hline \multicolumn{1}{|c|}{ Purpose } & \multicolumn{1}{c|}{ App } \\
\hline Digital donation & Samaritan, N=5_Helping Heart, WeShelter, Homeless Donation Meter, Give\&Go \\
\hline Direct support & ActionHunger, OurCalling, Streetchange \\
\hline $\begin{array}{l}\text { Information } \\
\text { latform }\end{array}$ & $\begin{array}{l}\text { StreetLight Chicago, HelpFinder, Link-SF, Shelter Space, Homeless Resources_-Strappd, Nextmeal.co.uk, } \\
\text { Chalmers, Mokli, Kältehilfe Berlin, strassenhilfe-hamburg.de, AskLizzy }\end{array}$ \\
\hline Mental health & Concrn \\
\hline Security & Streetlink \\
\hline Reconnection & Miracle Messages, Lease Up \\
\hline
\end{tabular}

Table 1. Overview of digital support for homeless neighbors

concentrate on whether an app works because they need to take care of fundamental issues in life [I1].

The analysis of the situation, the apps, and the interviews led us to the following conclusions. First, we found a lack of solutions for direct digital donations in our context (Germany). The lockdown aggravated the situation and dramatically increased the need for digital contactless support and clarified the need to develop a new solution. Second, we learned that even if there are good intentions behind the development of digital services for homeless neighbors, misuse can happen, or prejudice can be affirmed. Third, we realized that we had to embed our development within the social context to be able to consider the particular stakeholder needs that are relevant for the design. Finally, by also considering the theoretical foundations that we outlined in section 2, we realized that it is important to understand what it means to be responsible regarding the context.

\subsection{The digital donation concept "OpenStreetPay"}

In the following, we present the intermediate design of the digital donation concept in June 2020. Figure 2 illustrates the digital donation concept of OpenStreetPay. It consists of three main parts: the possibility to donate digitally, the SmallChangeCard, and the merchant app. A homeless neighbor will receive the SmallChangeCard from OpenStreetPay's homeless aid organization partners (cf. Figure 3, V8). The employee/volunteer of the homeless aid organization informs the homeless neighbor about the code of conduct, where they can use the card (including providing a map of all store locations), and what kind of information is collected about them (cf. Figure 3, V5, 6, $7,8)$. When they agree to these terms, the registration is completed, and the card is given to them. The SmallChangeCard is already loaded with $€ 20$, the monthly amount each cardholder will receive from the solidarity donation pot. Furthermore, the cardholder can individually collect money with the card up to $€ 130$ per month (this aspect needs to be checked due to financial regulations) (cf. Figure 3, V4). When there is money on the SmallChangeCard, the cardholder can buy the products they want at the selected shops (cf. Figure 3, V3). The SmallChangeCard can only be redeemed at OpenStreetPay's (initial) partners (cf. Figure 3, V8). In selecting the shops, the team made it a priority that the homeless neighbors would be treated well (cf. Figure 3, V8). The cardholder is not obligated to hand in the card after a certain period. The decision as to when a person in need has outgrown the conditions to receive a card is made in a joint discussion (cf. Figure 3, V3, 5). The donation shall be made in two different ways. The first option is a solidarity donation either via the website without downloading an app or registration or using the app for registered donors (cf. Figure 3, V6). The second option is donation on the street individually and directly to the homeless neighbors via the app or website. Further alternative forms of donations are currently under consideration, such as applying crowdfunding. To ensure appropriate security and trust, the team decided to work with a financial service provider that processed the transfer of money. It is essential to the team that this provider meets the values (cf. Figure 3, V8).

\subsection{The influence of values on the design}

As OpenStreetPay tries to enable digital donation, it affects and transforms the usual donation interaction known and practiced over thousands of years. Thus, beyond the provision of technical components, the socio-technical transformation must be anticipated and the insights embedded into the artifacts. The main changes are (a) the donator and the recipient do not necessarily meet each other, (b) in order to make use of the received money, the recipient has to possess a card, (c) a network of stores is required and who accepts and processes the card for payment is communicated, and (d) secure financial support and compliance to legal requirements is additionally required. These changes raise many design decisions, for example, who should receive how much money, where can the homeless neighbors spend the donated money, or how to design the digital donation interaction? By addressing certain decisions during the design process stepwise, the team realized that general discussions about fundamental 


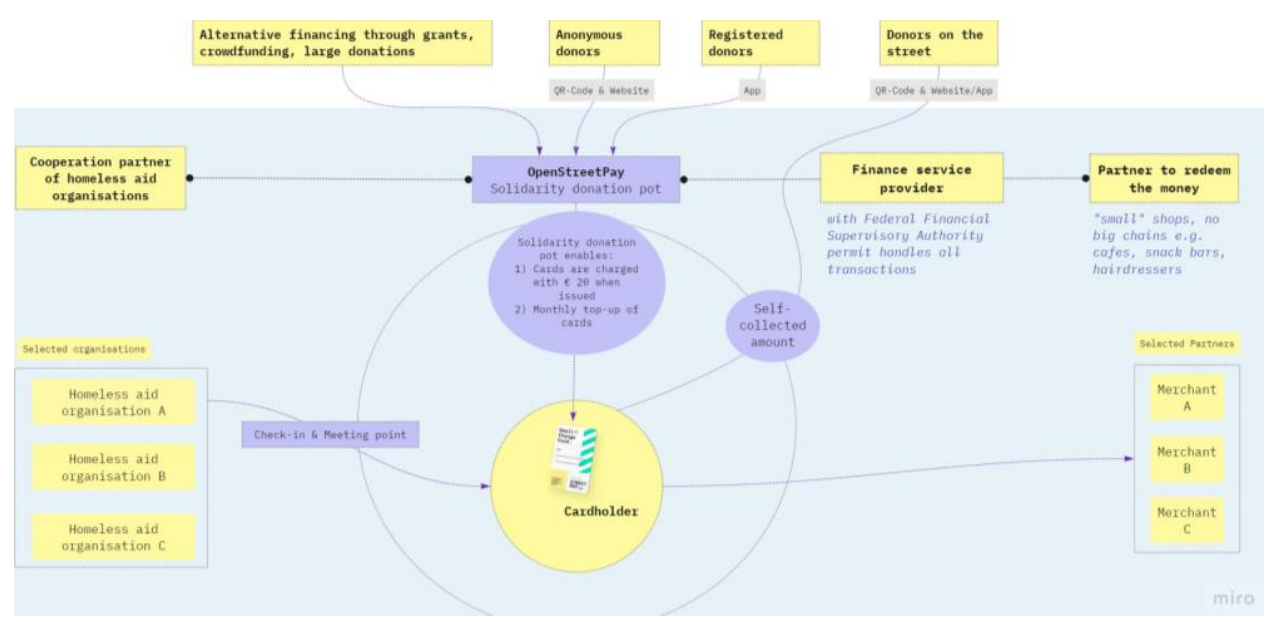

Figure 2. The digital donation concept of OpenStreetPay

positions emerged and hindered the progress of the whole project. Hence, it became apparent that the implicit values that guide the design have to be made explicit. In the following, we describe the values that the team developed and refined over time. An overview of the values is provided in Figure 3. We also show the relationship between the values, the design decisions, and further influences.

The first value captures the topic of humanness (cf. Figure 3, V1): "Be human. In everything we do: we do it out of humanity and with passion." The decision for this value covers the main motivation for becoming involved in this project to empower vulnerable people and is comparable to the value of human welfare from Friedman et al. [11]. Additionally, one of the main motivations for donors is to support humanness with a donation via OpenStreetPay. Also, from the perspective of homeless aid organizations, the participants of the survey see a good opportunity in OpenStreetPay, as the concept provides a low risk of infection during COVID19, creates a high-quality infrastructure, and boosts solidarity. In the interviews, the team gained deeper insights regarding the questions of whom to help and how to help [I3, I5, I6, I7]. According to one interviewee, this is a highly emotional topic, and the team needs to decide what its core interest and position is [I8]. These insights helped the team to develop the following two values (cf. Figure 3, V2, 3), which are closely linked to supporting humanness.

The second value is "Respect dignity. We treat each other, our partners, and each of our homeless neighbors with respect. Without exceptions" (cf. Figure 3, V2). This has multiple origins and addresses aspects that were raised in the quantitative analysis and expert interviews. It is similar to the values courtesy, freedom from bias, and identity, with a focus on the prevention of stigmatization and prejudice [11]. As previously explained, one of the most controversial aspects was who receives the money. Via the statements of donors, the team found that the identity of the recipients matters to some donors. One of the participants in the study wished explicitly for "no donation to addicts." As explained previously, the team learned from the interviews with homeless aid organizations the meaning of this discussion and the different perspectives $[13, \mathrm{I} 5, \mathrm{I} 6, \mathrm{I} 7]$ and therefore developed their message [I8]. For the OpenStreetPay team, it is important to help everyone who needs help and to respect their circumstances and themselves, even if this might decrease the willingness to donate for some donors. Further discussions and design decisions influenced by V2 are: A donor raised the issue that scanning the homeless neighbor for donation is disrespectful.

This aspect was thoroughly discussed in the design of the user experience for enabling individual donation. Furthermore, the team learned more about how to avoid stigmatization and prejudices (e.g., not every person likes to beg). Due to the solidarity donation option of OpenStreetPay, begging can be avoided [I3].

Value three is closely connected to value two and emerged in the discussion about how the team wants to help from the start in order to serve autonomy [11]: "Reach out. Small amounts of money make everyday life easier for our homeless neighbors. We enable selfresponsible care" (cf. Figure 3, V3). In the quantitative survey, the team gathered an understanding of the donors' wishes. For some of them, it is important to decide what can be bought by homeless neighbors with the donated money. According to V3, it is the team's goal to give people back self-autonomy and responsibility with small amounts of money. Considering the opinion of the homeless aid organizations, this led to the design decision not to limit the range of products in the participating stores. 


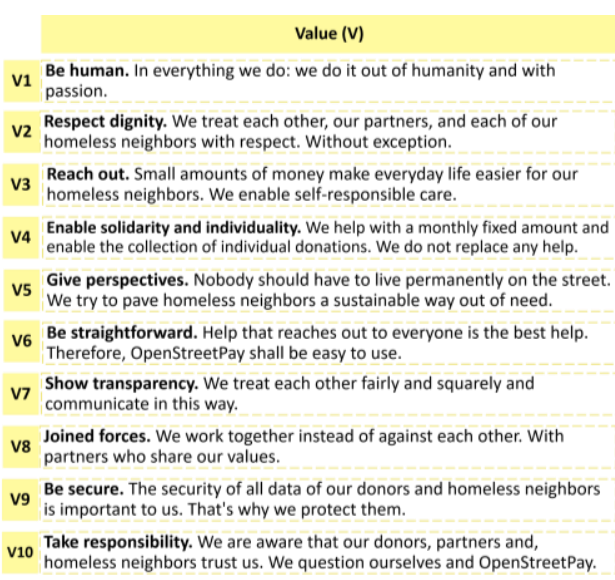

\begin{tabular}{|c|}
\hline Further Influences \\
\hline Branding, Selection of partners, Way of working as team \\
\hline $\begin{array}{l}\text { Branding, Selection of partners, Recipients of } \\
\text { SmallChangeCard }\end{array}$ \\
\hline Branding, Selection of partners \\
\hline $\begin{array}{l}\text { Legal form, Back-end, Branding, Selection of } \\
\text { partners/card, Concept of OpenStreetPay }\end{array}$ \\
\hline $\begin{array}{l}\text { Strong connection to homeless aid organizations, } \\
\text { Concept of OpenStreetPay }\end{array}$ \\
\hline $\begin{array}{l}\text { Communication with plain language and illustrations } \\
\text { (e.g. code of conduct), UX Design }\end{array}$ \\
\hline Branding, Communication \\
\hline $\begin{array}{l}\text { Partner selection and, diversity of shops, Concept of } \\
\text { OpenStreetPay }\end{array}$ \\
\hline $\begin{array}{l}\text { Back-end, Selection of and, cooperation with money } \\
\text { transfer partners, Data analysis only if needed }\end{array}$ \\
\hline $\begin{array}{l}\text { Way of working as team, Continuous reshaping of values } \\
\text { and concept, Measuring impact for social ecosystem }\end{array}$ \\
\hline
\end{tabular}

Figure 3. The values of OpenStreetPay

Value four captures the form of donation and has the aim to: "Enable solidarity and individuality. We help with a monthly fixed amount and enable the collection of individual donations. We do not replace any help" (cf. Figure 3, V4). This donation-specific value and decision is an adaption to the insights from the donors' wishes, the feasibility assessment of the homeless aid organizations, and insights from the interview with the lawyers. It stems from a toggling between different options on the design path. The team started with the idea of an individual form of digital donations (without financial limit), changed it to a solidarity-based concept in the hackathon ( $€ 5$ per day; $€ 150$ per month), and ended up with the design of a mixed concept ( $€ 20$ per month on solidarity base, up to $€ 130$ collection on their own) after performing the acceptance test and expert interviews. There are multiple reasons for this. First, an important legal aspect is that the donation of money needs to be reported. Handing over cash is still unregulated, but in switching to a cashless digital donation, the regulations of additional earnings need to be met (a maximum of $€ 150$ a month if you receive basic financial support in Germany) [I3, I5, I9]. Therefore, it is important for the team that OpenStreetPay does not cause any deductions or replacement of other sources of financial help. Second, the team faced substantial uncertainty about whether the required monthly amount in the solidarity donation pot would be continuously reached for solidarity-based donations. If each homeless neighbor received $€ 5$ every day, this would make $€ 150$ a month per person and $€ 286.500$ a month just for Hamburg [I6, I8]. From the donors' perspective, the data gathered presented the following picture: With anonymous donations through OpenStreetPay, the donors could plan the time of donation. The most preferred variances, based on our analysis, are weekly (23.47\%), monthly
$(30.61 \%)$, or on an irregular basis $(30.61 \%)$. The average donation amount is $€ 6.52$. The voices from homeless aid organizations regarding solidarity donation were also divided (seven for the concept, two against [I6, I7]). Hence, the team was reluctant to expect this constant high amount from the solidarity pot and decided to combine the two donation options [I6]. Third, it was also added that some homeless neighbors still need cash, and there is a risk that it might no longer be available. Therefore, it was important to the team that they did not want to replace any kind of donation. Changing to digital donations with both options makes donations individually explicit and analyzable. The team learned that it is vital to focus on existing regulations, like the additional earnings border, in case you receive financial aid from the government. Due to these aspects, the team started analyzing existing governmental regulations and talked to a pay tech lawyer [I11]. Normally, it is necessary to get an e-money license, but there are some exceptions that might fit for OpenStreetPay: Either the local area where the SmallChangeCard operates needs to be reduced according to a specific postal code area, or OpenStreetPay needs to make sure that the transferred money is only used for social causes. An alternative would be to work with an organization with an e-money license [I11].

For the fifth value, the team discussed the impact of OpenStreetPay and how they wanted to offer more than financial support to support freedom from bias [11]: "Give perspectives. Nobody should have to live permanently on the street. We try to pave homeless neighbors a sustainable way out of need" (cf. Figure 3 , V5). The donors highlighted that only offering money is not appropriate for vulnerable people; some donors mentioned that existing structures are important. Also, when someone donates with cash, there is always a direct interaction between the donor 
and the recipient. With a digital donation, this can change. Therefore, it was important for the team to understand the meaning for the donor (and the impact for the homeless neighbor). The donors' opinions were mixed. Their opinions regarding the local donation relation were mixed as well, but it seems that this was more important for them. Members of the homeless aid organizations have expressed their concern that some homeless neighbors who benefit from personal contact might suffer from this decrease in human interaction. As the team is aware of this unintended effect, it is determined to find a solution tailored to both the donors' and the homeless neighbors' different stages of need for contact with each other. Additionally, contact with homeless aid organizations will be fostered by distributing (and managing) the SmallChangeCard (cf. Figure 3, V8).

To enable the use of OpenStreetPay for everyone, the team discussed value six, which shall support universal usability [11]: "Be straightforward. Help that reaches out to everyone is the best help. Therefore, OpenStreetPay shall be easy to use" (cf. Figure 3, V6). This means that donating shall be as easy as possible. Most donors $(70.41 \%)$ would prefer to donate flexibly via smartphone or when they meet a homeless neighbor (52.04\%). Also, rounding up in the supermarket $(58.16 \%)$ or a proportionate donation when purchasing goods $(57.14 \%)$ seems to be interesting. Initially, the team decided to focus on the mobile app. The team found that installing an app, creating an account, long registry processes, too many authentications, signing contracts, or only one payment method can harm the willingness to donate. Hence, the team added a second interface to the concept: a web-based variant for donation. The interviewees of the homeless aid organizations highlighted that language problems and the need for different languages should be considered, and some homeless neighbors might have access barriers (due to physical and psychological restrictions) [I3, I5, I6, I7] . Therefore, it can be helpful to work with welfare worker to distribute the SmallChangeCard and use plain language and illustrations [I3, I5].

Transparency (value seven) was also an aspect the team discussed in terms of values. It is closely linked to trust [11]: "Show transparency. We treat each other fairly and squarely and communicate in this way" (cf. Figure 3, V7). Some donors want transparency of payment and donation processes (with little to no administration costs) as well as visibility of the number of beneficiaries in need. This is important for the team under the constraint of ensuring the dignity of the homeless neighbor (cf. Figure 3, V2).

It became clear during the discussions of other values that collaboration with others is irreplaceable.
Hence, the team developed value eight: "Joined forces. We work together instead of against each other. With partners who share our values" (cf. Figure 3, V8). It is important for donors that existing homeless aid structures will not be ignored because of OpenStreetPay. Competition with other parties and the risk of losing contact with homeless neighbors should be avoided. One of the motivations to work with homeless aid organizations was the concern about decreased personal contact (cf. V5). Due to these aspects, the collaboration with homeless aid organizations became a core element of the concept. Furthermore, it was highlighted that it might be helpful to work with more prominent and trusted organizations, like large grocery stores or banks [I2]. Due to the high regulatory need, the team started contacting money transferring organizations. The team learned that there are many kinds of possibilities to develop a card, but they have different costs [I12]. During this process, the team became aware that the decision about which company to collaborate with was going to be a challenge, particularly regarding the size, values, and motivation of the corporations. Therefore, they are still working on the partner management and will start with smaller cafés and restaurants to ensure that they share the values, which has an impact on V3 and decreases the heterogeneity of products to buy with the card.

As the team is working in a very sensitive area, privacy [11] is one of the core values (value nine): "Be secure. The security of all data of our donors and homeless neighbors is important to us. That's why we protect them" (cf. Figure 3, V9). Participants of the homeless aid organizations stated that they feared the collected data might be misused to disperse homeless neighbors from their shelters. This could be the case, for instance, if location data were collected, or the approximate location could be determined via fitting algorithms [I5, I9]. Therefore, all technical elements need to be secure. Also, the design decision was made to only collect and analyze data if necessary. However, registration of the homeless neighbors is necessary for compliance with laws [I2]. Thus, the team decided to use photos and names. This design decision could become challenging, as could other authentication techniques [I3, I7, I9]. Some homeless neighbors might not be willing to register [I5, I9]. For the donors, security and trust are especially important. The requirements start with a wish for additional information on our website, data protection, encrypted data transfer, and technology partners that are known, secure, and proven. While discussing this value, the team also discussed the required technology. Therefore, the team raised the question of whether a blockchain-based solution might be the right choice. 
However, the team decided that this solution was inappropriate because they are working with payment card providers and an existing infrastructure.

As mentioned above, the findings from the empirical research became part of the value discussion. However, value ten was not based on the empirical research, but it was derived from VSD. Values are evolving over time, so the team needs to question themselves and their values regularly [11]: "Take responsibility. We are aware that our donors, partners, and homeless neighbors trust us. We question ourselves and OpenStreetPay" (cf. Figure 3, V10). To operationalize the values, the team decided to develop a code of conduct for every stakeholder group.

\subsection{Reflection and formalization of learnings}

Regarding RQ1, we formalize our learnings as follows: (1) OpenStreetPay as one instance of a digital donation concept for homeless neighbors anticipates a very sensitive and difficult transformation of a social practice for vulnerable people that has persisted for thousands of years. It changes the method of donations and depends on the willingness of homeless neighbors to adopt and use it. (2) Developing a solution for this field requires a discussion of biases and prejudices to avoid a negative impact and a reinforcement of stigmatization. (3) The socio-technical complexity of the context requires a comprehensive concept that goes beyond software from the beginning onwards. It requires a lot of stakeholder knowledge and involvement, financial sustainability, and a stable, easy-to-use app. Many of the involved stakeholders suffer from high pressure due to limited resources, and wrong steps might not be forgiven. Therefore, understanding the stakeholders and their social ecosystem is crucial to avoid early failure [5]. (4) The establishment of an ecosystem network is essential to include expert knowledge about legal, security, and service provision aspects. While we assume that learning no. 1 to 4 can be generalized to other contexts, we also highlight that the development of a digital donation concept should consider the local particularities of the context due to the high relevance of the social context and stakeholders' perspectives.

The stakeholder-oriented and value-based process of developing a DSI for vulnerable people (RQ2) can be challenging, especially when prejudices and difficulties in accessing vulnerable people occur. To develop a DSI for vulnerable people, we formalize our learnings as follows: (1) It is important to understand the living circumstances of the vulnerable people, their social ecosystem, as well as the prejudices the vulnerable people meet while facing other stakeholders. (2) Our process showed that inscribing values into the design of a DSI is a good starting point to support vulnerable people and challenge biases and prejudices. The values are the basis for design decisions and planned collaboration patterns. (3) The discussion about the values also revealed unintentional ones of the DSI, which the team might not have encountered so quickly without a detailed discussion of them. (4) As described in section 4, the decision to develop values was based on recurring discussions, which are the foundation for the development. Once the team found common ground for the values, it was possible to focus on the transformation and to avoid failure due to unresolved tensions among underlying values. However, this also meant that certain requirements could not be considered in the design process in order to avoid contradicting the values.

\section{Discussion and conclusion}

Our study includes several contributions to IS research. First and related to RQ1, our study is one of the first studies describing the development of a digital donation concept and aiming to develop design knowledge for this field. Our study also advances research, as it includes a dedicated discussion of values, which was missing in prior studies [22]. The first steps of accompanying the OpenStreetPay project allowed us to reflect the design of a concept that allows digital donations to homeless neighbors. While we acknowledge context-specific factors influencing the design, we began to formalize our learnings (see section 4.4), which might be useful for others developing DSI for other vulnerable groups or those in different regions. In particular, the integration of the stakeholders in the design process allowed us to understand their needs and consider their value perspectives. Without anticipating these multilayered aspects from the empirical research, the extension of cash donations by digital donations might fail. Failures in such contexts might have a significant impact and lead to mistrust and refusal of further activities.

During the process of developing a value-based and stakeholder-oriented DSI (RQ2), we learned how VSD influences the design of DSI for vulnerable people. The work of Friedman et al. [11] served as a basis for integrating values into the design process. We provide another example of how their approach can support the design process, in our case, for a DSI for vulnerable groups. This could be leveraged for other DSI initiatives, as it exemplifies the idea of how to develop DSIs responsibly. Furthermore, the high relevance of values in the design process raised the question of how design goals and principles from 
ADR and values from VSD are related to each other. So far there is no clear answer to this question. Purao and $\mathrm{Wu}$ [14] do not see values as a design principle. We would agree with this assumption to a limited extent. If values have a strong influence on the design, as in the case of DSI, they could become part of them in an abstracted manner. This discussion points at this intersection as an interesting area for future research.

Our research results are limited due to the methods and the focus we chose. Our research focuses solely on the project OpenStreetPay and the context of Germany. In other countries like the USA, similar ideas and prototypes exist, which were also considered during the design process. Furthermore, we have not evaluated the idea with homeless neighbors to understand what will support them most. This will be our next step. An initial pilot test with homeless neighbors is planned, and the impact and success of OpenStreetPay in the social ecosystem will be measured.

\section{References}

[1] https://wirvsvirushackathon.org/jury/.

[2] BR24, Immer mehr Menschen in Deutschland zahlen bargeldlos, 02.05.2020.

[3] Brey, P., "Values in Technology and Disclosive Computer Ethics", The Cambridge handbook of information and computer ethics, 4, 2010, pp. 41-58.

[4] Buck, C., A. Krombacher, and K.M. Wyrtki, "How Digital is Social? Taking Advantage of Digital for Social Purposes", ECIS, 2020.

[5] Burmeister, F., P. Drews, and I. Schirmer, "Leveraging Architectural Thinking for Large-Scale E-Government Projects", in ICIS. 2019: Munich.

[6] Burrows, R., A. Mendoza, L. Sterling, T. Miller, and S. Pedell, Evaluating Ask Izzy: A Mobile Web App for People Experiencing Homelessness, 2019.

[7] Eckhardt, J., C. Kaletka, and B. Pelka, "New Initiatives for the Empowerment of People with Activity Limitations - An Analysis of 1,005 Cases of (Digital) Social Innovation Worldwide", in Universal Access in Human-Computer Interaction. Methods, Techniques, and Best Practices, M. Antona and C. Stephanidis, Editors. 2016. Springer International Publishing: Cham.

[8] European Commision, Social Protection \& Social Inclusion: Homelessness, 01.07.2020.

[9] Flanagan, M., D.C. Howe, and H. Nissenbaum, "Embodying Values in Technology: Theory and Practice", Information technology and moral philosophy, 322-353, 2008.
[10] Friedman, B., Human Values and the Design of Computer Technology, Cambridge University Press, 1997.

[11] Friedman, B., P.H. Kahn, and A. Borning, "Value Sensitive Design and Information Systems", The handbook of information and computer ethics, 2008, pp. 69-101.

[12] Humphry, J., Homeless and Connected: Mobile Phones and the Internet in the Lives of Homeless Australians, ACCAN, Sydney, 2014.

[13] Keijzer-Broers, W. and M. de Reuver, "Action Design Research for Social Innovation: Lessons from Designing a Health and Wellbeing Platform", ICIS, 2016.

[14] Purao, S. and A. Wu, "Towards Values-Inspired Design: The Case of Citizen-Centric Services", in ICIS. 2013: Milan.

[15] Rhoades, H., S.L. Wenzel, E. Rice, H. Winetrobe, and B. Henwood, "No Digital Divide? Technology Use Among Homeless Adults", Journal of Social Distress and the Homeless, 26, 2017.

[16] Sein, M.K., O. Henfridsson, S. Purao, M. Rossi, and R. Lindgren, "Action Design Research", MISQ, 35(1), 2011, p. 37.

[17] Simon, J., "Value-Sensitive Design and Responsible Research and Innovation", S.-O. Hansson. The Ethics of Technology - Methods and Approaches, 2016, pp. 219-236.

[18] Sowa, F., B. Rösch, T. Holzmeyer, M. Neberich, F. Opferkuch, K. Proschek, R. Reindl, J. Scheja, and S. Zauter, "Digitalisierung für alle? Zur Auswirkung digitaler Angebote auf Teilhabechancen von Wohnungslosen", Soziale Passagen, 87(3), 2020, p. 365 .

[19] United Nations, Sustainable Development Goals.

[20] United Nations, COVID-19 and Human Rights We are all in this together, April 2020.

[21] van den Hove, S., J. McGlade, P. Mottet, and M.H. Depledge, "The Innovation Union: A Perfect Means to Confused Ends?", Environmental Science \& Policy, 16, 2012, pp. 73-80.

[22] Whittle, J., M.A. Ferrario, and W. Simm, "Community-University Research: A Warts and All Account", in Into the Wild: Beyond the Design Research Lab, A. Chamberlain and A. Crabtree, Editors. 2020. Springer International Publishing: Cham. 